\title{
The Influence of Gender Stereotype on Students in Primary School Chinese Teaching Materials
}

\author{
Yining Feng ${ }^{1, \dagger}$, Zihan Zhan ${ }^{2, \text { a, }},+\dagger$ \\ ${ }^{1}$ Department of Psychology, Miami University, Oxford, Province 45056, the People's Republic of China. \\ ${ }^{2}$ College of Foreign Languages and Literature, Southwest Minzu University, Chengdu, Province 610000, the People's \\ Republic of China. \\ *Corresponding author email: ${ }^{a}$ zhanzihan@stu.swun.edu.cn \\ These authors contributed equally.
}

\begin{abstract}
Chinese educational textbooks not only have the functions of cultivating students' listening, hearing, reading, and writing, but also are the carrier for students to correctly understand the world and connect with the outside world. However, some implicit problems of gender stereotypes still appear in the textbook. As a language, Chinese is not just a tool, the cradle of mankind. Therefore, Chinese has been of certain significance in guiding children to form social gender awareness and establish gender equality awareness. Therefore, how to choose the gender role in Chinese textbooks has an important role.
\end{abstract}

Keywords: Primary school, Chinese textbooks, gender stereotypes, primary education.

\section{INTRODUCTION}

\subsection{Background}

\subsubsection{Gender Stereotypes and Textbook}

Gender stereotypes are a belief in the hypothetical traits of men and women, which is present in both sexes and has both positive and stereotypes. For example, positive female stereotypes identify women as kind, instructive, and thoughtful. Instead, being negative, they are viewed as indecisive, passive, and too emotional. Similarly, the stereotype is also assumed that males have both positive and negative characteristics. For example, seeing men as decisive, confident, and positive, but also aggressive, feeling dull, and arrogant.

First, for China, the gender classification of the social population is simple in structure and does not have a complicated hidden structure. Second, gender stereotypes are quite consistent in the same social culture or uniform group. Third, gender stereotypes are often not consistent with objective facts and, therefore, also known as gender bias. Sex stereotypes are important factors influencing individual socialization. In classroom teaching, gender stereotypes can also have implications for student learning. The learning Chinese textbook is the first and most formal textbook that children encounter after entering elementary school. The various information conveyed in the book will directly affect students' cognition and understanding of things. Primary school Chinese textbooks function as a tool and have humanized teaching characteristics. It not only has the function of teaching students listening, speaking, reading, and writing, but also has the function of influencing students' various qualities. As a tool, Chinese textbooks improve students' learning ability and enable them to become knowledgeable and capable; its humanities are to actively play the role of humanistic education, absorb the rich cultural spirit contained in Chinese, cultivate sentiments, improve the state of life, and form a complete personality.

\subsubsection{Research Aims, Meaning and Issue}

Achieving gender equality is always an inescapably crucial problem in education. Its implementation needs the comprehensive integration of all sectors of society and six-year primary school education accounts for the most important stage of children's growth. The information conveyed by the Chinese textbooks in primary schools will greatly affect the formation of students' gender ideological forms. Therefore, a comprehensive analysis of gender orientation in Chinese textbooks in primary schools is of great significance to students, schools, teachers, and society. This paper 
aims to analyze the issue of gender equality in Chinese primary educational textbooks and propose corresponding teaching countermeasures in order to develop students' concepts of gender equality while making full use of teaching materials.

Chinese textbook is a combination of instrumentality and humanism. As the link between the classroom and life, the Chinese textbook is not only a subject but also an indispensable communicative tool. Language is a combination of instrumentality and humanism. The characters portrayed in the textbooks are unconsciously perceived and imitated by children as they read. In addition, primary school students are at a critical stage in the formation of gender awareness and gender evaluation, and the overly dominant image of men as inferior to women in textbooks can have a great impact on them and lead to incorrect values. Inequality in the distribution of male and female roles in Chinese textbooks.

Xiaobin Zhu, a scholar, studied the elementary Chinese textbooks of the 1980s in China and found that the ratios of male to female in the Renminbi, the four provinces, and one city, and the Zhejiang edition were 77.7:13.2, 69.0:14.9, and 53.3:21.7, respectively [1]. He analyzed the primary language textbooks (12 volumes in total) of the Renminbi edition from 1994 to 1998 (six-year system), it was found that "the total number of selected texts describing or including characters (including anthropomorphic characters) was 149, involving 236 characters (including anthropomorphic characters), of which 55 (including female) appeared in female, accounting for only $23.3 \%$ of the total number of characters in the texts; 177 (including male) appeared in male, accounting for about $75 \%$ of the total number of characters"[1]. The number of male characters (including males) was 177 , accounting for $75 \%$ of the total number of characters. The number of women appearing in Chinese textbooks is very small, and where they do appear, the proportion and degree of their presence vary.

The ideas of male superiority and female inferiority conveyed in Chinese textbooks conflict with the gender equality now promoted. In Chinese textbooks, men are usually portrayed as responsible, strong, and positive, while women are usually portrayed in negative terms such as soft, quiet, and dependent. Moreover, the two sexes are subsumed into their different career choices, with men often encouraged to take up jobs that require long hours of physical exertion, such as firefighters and police officers, while the professions that are recognized as more suitable for women are patient, meticulous and maternal, such as nurses and teachers. But today, women should not be labeled in books in such a stereotypical and negative way; men and women enjoy equal opportunities to achieve vocational success. And this kind of portrayal can very easily lead primary school children to have a fixed image of themselves and imprison their minds.

\section{LITERATURE REVIEW}

\subsection{Domestic Research}

Before really getting into the information on gender equality provided by China in teaching materials, people need to understand that there is serious gender discrimination in the same reading materials for children. As mentioned in an article written by $\mathrm{X} \mathrm{Wu}$ and $\mathrm{Z}$ Zheng, a large number of children's books and periodicals have serious gender discrimination [2]. First, in investigating some fairy tales for children to read, men are twice as likely to act as protagonists than women, and boys are eight times more likely to be villains than women. And countless children's books are being labeled with gender by publishers intentionally or unintentionally, even subtly affecting the author's concept of writing [2]. First, in most fairy tales, the cover of fairy tales written for girls is almost always pink and full of butterflies and flowers. Fairy tales for boys are generally blue or gray and are full of dinosaurs and robots. From the perspective of audience needs, there are indeed some differences in the personalities of boys and girls, and the market should not ignore this differentiated demand. However, behind the seemingly reasonable remarks are the long-standing gender stereotypes. The market only further caters to these orientations and acts as a driver to strengthen them. Therefore, this culture full of sex discrimination should be gradually reduced and rectified.

One of the typical research is the comparison and analysis of several versions of primary school Chinese Textbooks in China, such as Hongxue Zheng, Shengnan Wang, found that in the domestic version of the story text, there have been many famous figures at all times, at home and abroad [3][4]. The proportion of men is very high. Men occupy almost all the Chinese and foreign leaders, heroes, great scientists, engineering and technical experts, great artists, etc. And women appeared a total of 10 times, five of them were martyrs. It can be concluded that, men are obviously dominant in quantity and quality, the profession is more creative and independent, and more embodies the advantages of mankind. Women show more the dark side of human beings [3][4].

To a certain extent, the children's books circulating on the market have caused some children to have gender stereotypes. In the research report published by Dai Li, it is mentioned that some grouping activities of 3-5 people in preschool education will greatly reduce the probability of the opposite sex forming a team together [5]. Boys will be consciously divided into the same group, and girls will be consciously divided into the 
same group [5]. This may be related to the gender bias caused by preschool children's books.

China began to study gender issues in textbooks in the 1980s. In 1988, Mingsu Wang 's paper "Gender Research in Children's Books" comprehensively analyzed the full set of primary school Chinese textbooks published by the people's Education Edition for the first time [6]. It opened the prelude to the analysis of gender research textbooks by individual scholars.

Xiaoqing $\mathrm{Yu}$ and Gailian $\mathrm{Lv}$ also conducted a certain investigation on the stereotypes of Chinese fairy tales [7]. They randomly selected 20 published Chinese fairy tales from the published works of Chinese fairy tales before 1980, 1980 and after. Research object. Statistics show that in fairy tales published before 1980, men appear more frequently than women, while fairy tales published in 1980 and later have no such significant difference. However, there are already a few fairy tales works that challenge the traditional division of roles between the sexes [7]. Regardless of the age of Chinese fairy tale works, the professional roles played by men are far more abundant than those played by women. But at that time, gender discrimination in China was gradually eliminated, and gender equality began to gradually become the mainstream. The gender stereotypes in Chinese fairy tales are no longer in line with social reality, but the traditional division of roles in fairy tales still affects children's gender concepts subtly.

After entering the 21 st century, the research and analysis of gender equality began to develop rapidly. $\mathrm{Xia}$ Liu found the gender bias in the illustrations through the research on the illustrations of primary school textbooks and concluded from the image of the mother in the text that the image of the mother was stereotyped [8]. Shuangshuang Bian not only studied the female role in Chinese textbooks but also studied the male role, which broadened the scope of gender research in textbooks and reflected the awareness of gender equality [9]. Jun Zhou also focused on the female perspective, starting with the female role in the teaching materials, discussed the formation and influence of gender role, analyzed it from the perspective of sociology, and put forward suggestions on this phenomenon [10].

\subsection{Overseas Research}

Due to the deep-rooted male chauvinism, people pay more attention to gender equality education later. country at home and abroad, the preliminary research on gender issues in textbooks only began in the 1940s and ended in the 1970s. The 1990s was the climax of its research. In the 1980s, American psychologists also studied gender roles in primary school textbooks, the primary school textbooks of Spain, Romania, France,
Sweden, and the former Soviet Union were selected we believe that there is a clear phenomenon of gender role inequality in these textbooks.

In recent years, feminist scholars have also studied gender problems in textbooks. In American textbooks, women 's roles are in both texts and illustrations very few times. The female role image in the text is mainly family women, which is an exhibition of intellectual women now it decreases with the increase of school level, and the women in the illustrations are mainly supporting roles.

Thus, foreign scholars generally believe that there are serious inequalities in the presentation of gender roles in textbooks, the number of men is far greater than that of women, the shaping of characters is too rigid, and men's social value and social status is fully affirmed, while women are largely ignored.

Children's picture books entered the Chinese market from European and American countries at the end of the last century. In just a dozen years, they have formed a good development trend and a stable readership. Ning Chen described the study of gender concepts in the publication of American children's picture books in this article in order to provide some help and suggestions for the current Chinese language teaching materials[11]. Children's picture books have been developed in European and American countries for more than 100 years. They are the main form of reading for preschool children. They play a vital role in children's personality education, aesthetic education, and social development. In Amazon's 2015 Book Rankings for Children, all books under the age of 6 on the list are picture books. In the huge market for children's picture books, imported editions account for about $80 \%$ of the market share, and most of them are award-winning classics that have been circulated abroad for a long time.

\section{RESEARCH METHODOLOGY AND FRAMEWORK}

Quantitative analysis: This method is based on the analysis of the gender distribution of male and female characters, illustrations, authors, title characters, etc. in textbooks, and provides a clear picture of the gender distribution in textbooks. In the area of textual analysis, the textual analysis of the characters whose gender has been counted in the textbook is used to go deeper into the text and to study the further message of the textbook.

The comparative approach: a cross-sectional comparison of textbooks is carried out on the data already collected. This will reveal more deeply the gender inequalities in textbooks.

This paper, based on the framework of theory-textbook analysis-impact analysis-advice, is 
widely collected relevant documents, draw lessons from past research results, on the basis of gender formation of the relevant theory, according to the current primary school Chinese textbooks in both sexes the number of characters, the quality, the tendency of an image, reveal all sorts of problems that exist in the Chinese textbooks, and influence. Finally, corresponding solutions to these problems are put forward.

The structure of the research is arranged as follows: The first part introduces the origin and significance of the research, combs, and reviews the previous literature on this topic, defines the relevant core concepts, and expounds the research ideas and framework. The second part is the analysis of gender culture and role in primary School Chinese textbooks. The third part analyzes the influence of gender orientation in textbooks on students according to the existing research conclusions and expounds on its positive and negative influence. The fourth part puts forward suggestions on gender bias in current Chinese textbooks for primary schools.

\section{ANALYSIS}

In the domestic original children's picture books, gender-related topics are basically normative education, that is, guiding boys and girls to recognize differences in body, temperament, social roles, and behavioral norms, so as to prevent them from becoming adults due to non-compliance. Gender norms become an "abnormal" heterogeneity. For example, it emphasizes the responsibility, bravery, adventure, self-confidence, and other traits of boys, and emphasizes the kindness, docility, understanding, and delicacy of girls. However, with the variability of human beings to social gender, people have realized that although physical gender differences exist, they are not enough to become a decisive factor restricting individual development patterns and social status. Therefore, under the premise of not violating the law, any gender image, gender behavior and gender role a person chooses should be equally respected. The frequency of appearance of male and female supporting roles in American children's picture books is nearly equal, that is, girls must appear where there are boys, and there must be adult women where there are adult men, and the numbers are basically the same. This virtually makes young readers realize that this is a world made up of people of different genders, which is incomparable to most domestic teaching materials.

Nowadays, in American children's picture books, it has become a clear and basic creative consciousness to balance the status and contribution of men and women in all aspects of social life. As the protagonists of picture book stories, whether children, parents or other adults of both sexes, they appear in various life scenes at the same frequency. The biggest difference is that there are more male protagonists than female protagonists in social life, but only a little more. This shows that the American children's picture book strives to present a world where the ratio of men to women is basically balanced. Children can intuitively feel in reading that no matter what kind of life scene-nature, social life or family life, men and women can be the protagonists and can lead their own stories forward. This is the direction that the current domestic textbooks need to refer to.

By observing the measures and actions taken by overseas regions on children's teaching materials, we can get some reflection and reference. First of all, in terms of policies, my country can choose to introduce some specific policies to help minors establish a concept of gender equality and protect some children who have doubts about their gender. In addition, as a carrier of children's education, curriculum materials play an important role in gender education. American elementary schools have accumulated a wealth of experience in the design and implementation of textbooks for gender equality education, which provides a reference for the curriculum design of gender equality education that can be implemented on textbooks in my country. In the same way, by learning from mature experience and lessons from other countries, my country's children's language textbooks can also tell students about gender concepts and correct practices against gender discrimination, and help students form an understanding of gender equality and anti-sex discrimination in their studies.

Finally, for a work that enters a textbook, it should be measured by different standards from different angles, including both content standards and formal standards. The education of truth, goodness and beauty that children receive in Chinese textbooks will form the spiritual background of their life. Because of this, teaching materials play a vital role in student education. Students' Chinese textbooks must first integrate the physical and mental development of children at different ages, but at the same time, they must not give up the difficulty, and the textbooks should not be made superficial and straightforward. Good textbooks should guide students to learn aesthetics, learn to think, learn to explore, learn to discover, and build such a system of mental development. The works selected into the textbook should have the value of aesthetic exploration and spiritual discovery. Only in this way can the children's correct thinking be cultivated.

\section{CONCLUSION}

In this article, discussing and analyzing the distribution and image of gender roles in domestic and foreign textbooks is the main purpose. In foreign countries, such as the United States, gender issues in textbooks have received some attention. Textbook writers intend to balance the distribution of men and women in textbooks in the editing process, which will 
give American children a strong understanding of gender equality and make it easier for them to build a gender-equal social relationship.

In China, the superiority of men over women is a social consciousness that lasted from a feudal society to modern times. Although in modern times, this gender system began to change from the bottom, it is also a long and tough historical process.

Improving gender inequality requires the efforts and education of several generations. Therefore, as the bearer and disseminator of culture and consciousness, textbook compilers and teachers need to rectify the negative parts of the existing textbooks in the process of compiling and using textbooks, and actively guide students to form a correct gender concept and make textbooks become the forerunner of advanced cultural concepts.

At the same time, China's textbooks should actively learn from the excellent models of other countries, take their essence, and discard their dross. The image of men being superior to women implied in education virtually affects students' gender consciousness and gender concept. Education, as a subsystem of society, should shoulder the essential task of gender education.

\section{REFERENCES}

[1] Xiaobin Zhu. "Looking at the Socialization of Children's Gender Roles from the Perspective of Three Primary School Chinese Textbooks in China- A Comparison with A Reading Textbook in the United States". Liaoning Education (12),31-33. doi: CNKI: SUN: LNJY.0.1994-12-017.

[2] X Wu \& Z Zheng, We Have All Gone Over the Sexism in Children's Books, Beijing News, [online] Available:https://www.bjnews.com.cn/detail/15561 5254315913.html.

[3] Hongxue Zheng, Research on Gender Roles in Chinese Textbooks for Primary Schools Published by the Protestant Education Edition (Master's thesis, Kashgar University), [online] Available: https://kns.cnki.net/KCMS/detail/detail.aspx?dbna me $=$ CMFD201901\&filename $=1018129111 . \mathrm{nh}$

[4] Shengnan Wang, A Study on the Rationality of Gender Role Differences in Primary School Chinese Textbooks Compiled by the Ministry of Education (Master' $\mathrm{s}$ thesis, Sichuan Normal University), [online]Available: https://kns.cnki.net/KCMS/detail/detail.aspx?dbna $\mathrm{me}=\mathrm{CMFD} 202002 \&$ filename $=1020747405 . \mathrm{nh}$

[5] Dai, L. "Research Status and Enlightenment of Gender Education for Preschool Children". Journal of China Women's University,
http://www.cssn.cn/kxk/etyj/201712/W020171225 585180379815, 2016.

[6] Mingsu Wang \& Jianmin Cui. “Gender Research in Children's Books: A Statistical Analysis of Chinese Textbooks in Primary Schools in China". Psychological Science Newsletter (05),47-49,1988.

[7] Xiaoqing Yu \& Gailian Lv, The Study of Gender Stereotypes in Chinese Fairy Tales, [online]Available:

https://m.xzbu.com/9/view-946589.htm

[8] Xia Liu, The Study on Gender Bias in Primary School Chinese Teaching Materials, [online]Available: https://kns.cnki.net/KCMS/detail/detail.aspx?dbna me $=$ CMFD2008\&filename $=2008153005 . \mathrm{nh}$

[9] Shuangshuang Bian \& Yi Zhuo. "The Study on Gender Role Stereotypes in Primary School Chinese Textbooks-Taking Chinese Textbooks for the Fifth and Sixth Grade-s of Primary School as An Example". Modern communication (14),186-188+65, doi: CNKI: SUN: XKJJ.0.2021-14-063

[10] Jun Zhou, An Analysis of Gender Roles in Primary School Chinese Textbooks, [online]Available: https://wap.cnki.net/touch/web/Dissertation/Article /10511-1014245987.nh.html.

[11] Ning Chen, The Study on The Concept of Gender in the Publication of American Children's Picture Books, [online]Available: https://www.1xuezhe.exuezhe.com/Qk/art/614305? dbcode $=1 \&$ flag $=2$. 